\title{
Modelagem para avaliação de desempenho ambiental em operações de manufatura
}

\author{
Modelling for environmental performance \\ assessment in manufacturing operations
}

\author{
Miguel Afonso Sellitto \\ Miriam Borchardt ${ }^{1}$ \\ Giancarlo Medeiros Pereira ${ }^{1}$
}

\begin{abstract}
Resumo: O objetivo deste artigo foi apresentar e testar um método de construção de modelos para a mensuração de desempenho ambiental em operações de manufatura. $\mathrm{O}$ método de pesquisa foi o estudo de caso múltiplo. $\mathrm{O}$ desempenho ambiental de uma operação de manufatura foi tratado como uma grandeza intangível, composta por cinco construtos latentes: emissões atmosféricas; efluentes líquidos; resíduos sólidos; uso de recursos naturais e gestão interna; e atendimento a legislações e certificações. Os quatro primeiros são de impacto direto, enquanto que o último foi considerado condição intermediária e necessária para os demais. Os significados dos construtos foram apreendidos por indicadores e mensurados qualitativamente por questionários respondidos por gestores de cinco operações: operação avícola, fabricação mecânica, fabricação de materiais elétricos, fabricação de rações e estamparia de aço. Os resultados foram estudados e comparados e forneceram subsídios para a eventual reformulação de estratégias de ação ambientais inseridas nas estratégias de operação das empresas.
\end{abstract}

Palavras-chave: Desempenho ambiental. Indicadores ambientais. Produção mais limpa. Gestão ambiental. Certificação ambiental.

\begin{abstract}
This paper presents and tests a method for building models to measure environmental performance in manufacturing operations. The research method was the multiple case study. Environmental performance of a manufacturing operation was treated as an intangible variant, composed of five latent constructs: atmospheric emissions, liquid effluents, solid waste, natural resources employment and management and legal requirements and certification compliances. The first four have direct impact on the environment and the last is accepted as a priority and necessary condition for the others. The meaning of the constructs was appraised by indicators and assessed by questionnaires answered by managers from five operations: chicken egg production, mechanical manufacture, electrical goods manufacture, animal food manufacture and steel stamping. The results were discussed and compared, providing some indicators for an eventual reformulation of environmental strategies of the enterprises studied, to be adopted within the enterprises operational strategies.
\end{abstract}

Keywords: Environmental performance. Environmental indicators. Cleaner production. Environmental management. Environmental certification.

\section{Introdução}

A preocupação formal com o meio ambiente é recente na história da humanidade. Esta preocupação tem se manifestado de modo mais acentuado a partir dos anos 1960. Diversos encontros mundiais foram realizados desde então, dos quais alguns podem ser realçados, por suas decorrências. Em 1972, foi realizada uma conferência mundial sobre Meio Ambiente, em Estocolmo. Em 1992, foi realizada a ECO-92, no Rio de Janeiro, promovida pela UNCED (United Nations Conference on Environment and Development). Neste, foi elaborada a Agenda 21, que passou a ser opção de referência na implantação de programas e políticas de preservação do meio ambiente e desenvolvimento sustentável. Dois encontros ocorreram: em Kioto, em 1998, no qual se discutiu o impacto das emissões gasosas ao meio ambiente e em Johannesburgo (Rio mais dez, em 2002), a conferência das Nações Unidas sobre ambiente e desenvolvimento sustentável (MACHADO, 1997; LUZ; SELLITTO; GOMES, 2006).

Um tipo de interação antrópica com o ambiente ocorre nas operações de manufatura. Aspectos ligando ambiente e operações passaram a ser mais intensamente discutidos à medida que cresceram as pressões legais e

\footnotetext{
${ }^{1}$ Programa de Pós-Graduação em Engenharia de Produção e Sistemas - PPGEPS, Universidade do Vale do Rio dos Sinos - Unisinos,

Av. Unisinos 950, CEP 93022-000, São Leopoldo, RS, Brasil, E-mails: sellitto@unisinos.br; miriamb@unisinos.br; gian@unisinos.br

Recebido em 23/6/2008 — Aceito em 25/2/2010
}

Suporte financeiro: A pesquisa foi financiada em parte pelo CNPq. 
de consumidores sobre questões ambientais. Segundo Donaire (1999), operações de manufatura podem responder a tais pressões com controle fim de tubo, instalando dispositivos que neutralizam os ataques ambientais, sem interferir no processamento; ou com controle no processo, reprojetado para reduzir pressões ambientais, reaproveitar materiais e racionalizar insumos e energéticos. Uma alternativa é a adoção do ecodesign, um conjunto de práticas de projeto orientadas à criação de produtos e processos ecoeficientes que tem como objetivo principal reduzir o impacto ambiental do produto nas fases do ciclo de vida: matérias-primas, produção, distribuição, utilização e destino final (FIKSEL, 1996; BORCHARDT et al., 2009). Outra é a implantação dos SGA (Sistemas de Gerenciamento Ambiental), os quais, entre outros requisitos, exigem modelos para a medição de desempenho ambiental, baseados em indicadores. Estes não são a expressão completa da realidade, mas uma simplificação que torna mais fácil e simples a comunicação de um assunto complexo, tal como o desempenho ambiental (LUZ; SELLITTO; GOMES, 2006).

Para Franke e Grithe-Senf (2006), o desempenho ambiental de uma empresa é medido pelo grau de alcance dos seus próprios objetivos ambientais. Melo e Pegado (2006) definem desempenho ambiental como a influência que uma operação industrial antrópica causa no ambiente, diferenciando-o de desempenho gerencial, que é a eficiência na condução de práticas preservacionistas ou mitigatórias. Zobel et al. (2002) definem desempenho ambiental como a informação analítica oferecida por um conjunto de indicadores que permite comparar entre si, ou contra uma referência externa, requisitos ambientais em setores de uma empresa ou em empresas de uma indústria.

Indicadores ambientais podem capturar dados complexos, originados de várias fontes e segundo vários modos de mensuração, e transformá-los em uma estrutura comunicável, tal como um índice global. Este índice é o topo de uma pirâmide informacional, em cuja base estão os dados primários de campo, de várias naturezas, e no meio estão os indicadores que os capturam e comunicam o desempenho ambiental. Mensuração permanente e comunicação do desempenho ambiental podem disseminar conhecimento e promover políticas que previnam problemas ambientais (HAMMOND et al., 1995). Melo e Pegado (2006) citam, entre outras, algumas vantagens de se ter um modelo formal para mensuração de desempenho por indicadores: (i) síntese e comunicação da complexa informação exigida para a gestão de sistemas ambientais; (ii) quantificação das lacunas, a diferença entre o desempenho atual e as metas de desempenho; e (iii) uso das lacunas para identificação de prioridades. Pegado, Melo e Ramos (2001) observam que alguns sistemas de medição dão mais importância a indicadores de eficiência de gestão do que aos efeitos ambientais. Kuhre (1998) afirma que a simples mensuração continuada do desempenho ambiental, por um modelo formal, permite melhorar os resultados da gestão ambiental, mesmo sem um sistema formalizado de gestão.

O objetivo deste artigo é apresentar o SBP (iniciais dos proponentes), um método para criação de modelos para mensuração de desempenho ambiental em operações industriais antrópicas. A mensuração pode ser uma medição de desempenho, quando é apoiada em variáveis físicas de campo, ou avaliação de desempenho, quando é apoiada em julgamento de especialistas. Os objetivos secundários são: (i) propor uma definição para a grandeza intangível desempenho ambiental; (ii) apresentar um método numérico para sua avaliação; e (iii) testar e refinar o método em estudos de caso repetidos. O modelo calcula para cada operação um índice global, entre $0 \%$ e $100 \%$. Os resultados de múltiplas operações podem ser comparados e usados para compor resultados sistêmicos em cadeias produtivas. Para teste e robustecimento, o método foi aplicado a cinco operações de manufatura: produção de ovos de galinha; produção de materiais elétricos; produção de forjados e usinados; produção de rações para frangos; e estamparia de peças metálicas. São delimitações de pesquisa: casos apenas em manufatura e avaliação de desempenho, não medição. As principais contribuições da pesquisa são o método de trabalho e os resultados específicos dos casos, não generalizáveis a outras operações. A pesquisa segue a linha iniciada em Luz, Sellitto e Gomes (2006).

Após a introdução, o artigo traz: (i) revisão teórica sobre mensuração de desempenho ambiental; (ii) metodologia de pesquisa e método de trabalho; (iii) resultados dos casos; (iv) discussão e contribuição dos casos ao tema; e (iv) conclusões e continuidade de pesquisa.

\section{Mensuração de desempenho ambiental}

A mensuração de desempenho ambiental surge na literatura em diversas fontes, das quais se citam algumas mais relacionadas ao método ora proposto. Cornforth (1999) propõe método para selecionar indicadores em uma única dimensão de análise, o uso do solo; Leeuw (2004) usa múltiplos indicadores para medir a qualidade do ar; Ramos e Melo (2006) usam avaliações por questionário de múltiplos aspectos ambientais e chegam a um índice agregado para o desempenho ambiental de uma operação corporativa; Tyteca (1996) e Thoresen (1999) propõem indicadores para medição e comparação de desempenhos ambientais entre operações empresariais; Gough, Castells e Funtowicz (1998) usam método de avaliação ambiental integrada no processo de tomadas de decisão ambiental; Zobel et al. (2002) fazem avaliações ambientais ao longo do ciclo de vida de materiais; Azzone e Manzini 
(1994) medem o desempenho de uma estratégia ambiental; Ammenberg, Hjelm e Quotes (2002) usam SGA para mensurar o desempenho ambiental; Dias-Sardinha e Reijnders (2001, 2005), Campos (2001) e Rosseto (2003) usam a estrutura conceitual do BSC (Balanced Scorecard) para formulação de estratégias e medição de desempenho ambiental em circunstâncias específicas; Ramos e Melo (2006) usam avaliações por questionário e chegam a um índice agregado de desempenho ambiental; Pegado, Melo e Ramos (2001) e Melo e Pegado (2002, 2006), propõem uma metodologia para medição de desempenho ambiental multidimensional; e Luz, Sellitto e Gomes (2006) usam o método multicriterial AHP (Analytical Hierarchical Process) para priorizar indicadores e formar um modelo de medição de desempenho ambiental em operações de manufatura baseado em medições físicas de variáveis de campo.

Segundo Cesaro (1992), a regulamentação sobre avaliação ambiental pode ser como a francesa, que avalia todas as operações, menos as listadas; e como as legislações italiana e brasileira, que listam as operações de avaliação obrigatória. Segundo Pegado, Melo e Ramos (2001), a avaliação do desempenho ambiental já é feita, em parte, por instrumentos, tais como a avaliação de impacto ambiental e a análise de risco ambiental. Pearson e Barnes (1999) contrapõem que a avaliação do desempenho ambiental não deve se limitar a relatórios e deve incluir multidimensões, representadas por indicadores de desempenho. Luz, Sellitto e Gomes (2006) dizem que a avaliação baseada em julgamento pode mudar conforme o julgador e o momento, o que não ocorre com medições baseadas em indicadores. Acrescenta-se que é difícil agregar resultados de relatórios, pois a avaliação final trará a subjetividade de quem agrega e julga os relatos. Por outro lado, Dale e Gerlak (2007) alertam que tem surgido uma tendência a avaliar progressos ambientais somente por dados quantitativos, apesar da inerente complexidade presente na gestão de recursos naturais. Os autores relatam casos observados de inconsistências e inconfiabilidades e enfatizam a necessidade de modelos estruturados para o uso de indicadores em medição de desempenho de programas ou estratégias ambientais.

Indicadores podem medir impacto ou pressão ambiental. Impacto ambiental é o efeito ou mudança causada no ambiente por atividade antrópica. Pressão ambiental é a medida da intensidade ou do potencial da atividade para causar o impacto. Por exemplo, fabricação de materiais elétricos exige verniz. O impacto ambiental é a contaminação de solo ou águas pelo verniz e é apreendido por grandezas fim, tais como a presença na água ou no solo. Pressões ambientais são apreendidas por grandezas meio, tais como que quantidade e com qual solubilidade a operação exige de verniz. Medir o impacto ambiental exige mais informação e o resultado é mais sujeito às condições basais do ambiente e efeitos complexos que várias fontes produzem. Por requerer menos informações, geralmente já disponíveis, gestores podem optar por medir apenas as pressões ambientais, não os impactos (MELO; PEGADO, 2006).

Modelos de medição podem incluir tanto modelos de avaliação de produtos, como de processos ou operações. Dois exemplos de modelos para produtos são a Pegada Ecológica (ECOBLOCK, 2006) e a Avaliação do Ciclo de Vida (OWENS, 1997). Para este artigo, interessam apenas modelos para operações. Até quanto se pesquisou, três modelos têm mais relação com o ora proposto: o ADAA (Avaliação de Desempenho Ambiental Ampliado); o modelo do World Resources Institute (WRI); e o da UNEP/UNESCO (United Nations Environment Programme - Programa Ambiental das Nações Unidas/ United Nations Education, Science and Culture Organization - Organização das Nações Unidas para a Educação, a Ciência e a Cultura).

O ADAA integra objetivos econômicos, sociais e ambientais de sustentabilidade de uma operação, por isto seus autores o chamaram de ampliado. O modelo considera seis construtos capacitadores (liderança, planejamento, pessoal, implementação, operações e controle) e três de resultados (econômicos, sociais e ambientais). O bloco de resultados ambientais inclui seis classes: materiais, resíduos, energia, efluentes e emissões (FRANKE; GROTHE-SENF, 2006). O modelo do WRI se aplica mais a grandes espaços, tais como territórios ou setores econômicos e explora quatro construtos: poluição do ambiente; redução de recursos ambientais; risco ao ecossistema; e impacto do ambiente no bem-estar humano. O modelo propõe indicadores respondendo a três questões para cada construto: o que está acontecendo com o ambiente; porque está acontecendo; e o que estamos fazendo a respeito (HAMMOND et al., 1995). O modelo UNEP/UNESCO pode ser sintetizado em: (i) definição do sistema a medir e seleção de indicadores básicos sócio-econômicos e ecológicos; (ii) agregação destes em índices de segundo nível, tais como atividade econômica, saúde pública, qualidade da água, vida selvagem, etc.; e (iii) agregação em dois índices de terceiro nível, descritores dos subsistemas ecológico e econômico-social. Alguns dos objetivos do modelo são: (i) calcular um valor agregado que caracterize o estado atual do sistema sob as perspectivas ecológicas e sócio-econômicas; (ii) permitir comparações objetivas entre sistemas distintos; (iii) ser base para escolha entre estratégias que modifiquem os sistemas, mas compitam por recursos escassos; e (iv) refletir mudanças de importância no tempo e no espaço (ROSSETTO, 2003). O método produz uma estrutura balanceada ponderada de indicadores. Bollmann (2001) salienta que o método não mede indicadores isolados ou separados 
por afinidade, mas cria um índice que os relacione e pondere, apontando as lacunas para o desempenho ambiental ótimo.

\section{A pesquisa: \\ metodologia e resultados}

Sellitto e Ribeiro (2004) sistematizaram a medição de objetos intangíveis complexos, tais como desempenho ambiental, estruturando o objeto em componentes. O ente de topo é o termo teórico, explicado por construtos latentes que se sustentam em conceitos explicados por indicadores, formando uma estrutura em níveis hierárquicos. A estrutura pode ser construída por teoria, conhecimento empírico ou opinião de especialistas. $\mathrm{O}$ desempenho assume a forma de um sistema de medições, desdobrado em subsistemas até o nível dos indicadores, que recompõem e medem o sistema como um todo, garantindo consistência e confiabilidade na medição. A proposta dos autores foi usada neste artigo. Também se adotou a conceituação dos autores: (i) avaliação (assessment) é o processo de mensuração de grandeza intangível baseada em julgamento categórico de especialistas sobre indicadores que descrevem a grandeza; (ii) medição (measurement) é o mesmo processo, porém baseado em medição física de variáveis de campo. A avaliação apreende mais aspectos do que a medição, pois o julgamento pode integrar diversos requisitos de desempenho em uma única categoria [péssimo, ruim, médio, bom, ótimo], mas implica a existência de alguma subjetividade inerente ao julgamento do especialista. A medição apreende apenas o conteúdo do indicador físico, abrindo mão de visões alternativas sobre o problema, porém é mais objetiva. Este artigo usou avaliação. O artigo seminal de Luz, Sellitto e Gomes (2006) usou medição, pois se valeu de indicadores medidos fisicamente em campo.

A questão de pesquisa foi: (i) como construir um modelo que permita a mensuração do desempenho ambiental de uma operação empresarial, intrinsecamente um objeto complexo e intangível? A resposta deve reforçar, refutar ou corrigir a hipótese de teste, o método SBP de modelagem de desempenho ambiental. Para questões do tipo como, Yin (2001) indica o método do estudo de caso. Para Roesch (1999), uma das contribuições do estudo de caso é expor regularidades de um objeto de pesquisa que poderão participar de uma futura teoria sobre o objeto. Para Eisenhardt (1989), o aprendizado oferecido por casos repetidos pode contribuir para a formulação de uma teoria fundamentada (grounded theory).

O objetivo principal de pesquisa foi testar o SBP, um método de construção de modelos para a mensuração de desempenho ambiental de operações antrópicas industriais. Os objetivos secundários foram: (i) identificar construtos latentes e indicadores que expliquem o desempenho ambiental da operação; (ii) distribuir importância relativa (cem pontos percentuais) entre os indicadores; (iii) avaliar categoricamente a situação atual dos indicadores e obter um índice final de desempenho ambiental da operação; e (iv) se houver, analisar as lacunas de desempenho, os construtos e indicadores que mais contribuíram para que o desempenho final não atingisse $100 \%$. O método de pesquisa foi o estudo de caso exploratório múltiplo. A contribuição foi a descrição específica de cinco casos que, se somados a outros, em profundidade e lateralidade crescentes, poderá expor regularidades do objeto e contribuir para uma futura teoria fundamentada. Eventualmente, pode-se chegar a um modelo generalista de mensuração de desempenho ambiental em operações industriais.

\subsection{O método Sellitto, Borchardt e Pereira}

O principal objetivo do SBP é capturar, por indicadores integrados, a complexidade presente em sistemas ambientais e a natureza sistêmica de sua manifestação. Reconhece-se a complexidade dividindo o objeto sistêmico complexo, o impacto ambiental da operação, em subsistemas, atribuindolhes importâncias relativas no impacto global e descrevendo-os por indicadores. Modificando-se a situação de um subsistema, devido às interações presentes, modificam-se as importâncias relativas e eventualmente os indicadores. Até quanto se pesquisou, a principal vantagem do método em relação a outros é a capacidade de adaptação a mudanças que ocorram na legislação, nos processos, nos materiais, nos produtos e a novos conhecimentos. Para tanto, reformula-se o modelo de avaliação, incluindo ou excluindo indicadores e mudando prioridades, sempre que mudarem as circunstâncias da operação.

São premissas do método: (i) o desempenho ambiental de uma operação antrópica pode ser desdobrado em construtos latentes que descrevem como as atividades da operação impactam o ambiente; (ii) os construtos podem ser apreendidos por indicadores; (iii) a prioridade dos construtos é variável e pode ser atribuída por gestores; e (iv) os indicadores podem ser agregados formando um índice global que oscila entre 0 e $100 \%$, para comunicação e comparação entre operações. $\mathrm{O}$ resultado final informa as condições instantâneas da operação, segundo as circunstâncias apreendidas pelo modelo, pode servir como série histórica e desempenhar a função de retroalimentação na tomada de decisões e na definição, avaliação e melhoria da estratégia ambiental da operação.

A definição dos construtos e dos indicadores ocorre em reuniões de grupo focado com especialistas em gestão ambiental, mediados por pesquisadores. Nos casos deste artigo, foram formados grupos de quatro e cinco especialistas que foram convidados a visitar 
e estudar cinco operações industriais em empresas que aceitaram sediar a pesquisa. Foram usados quatro construtos de impacto direto da pesquisa empírica de Luz, Sellitto e Gomes (2006): situação das emissões atmosféricas; dos efluentes líquidos; dos resíduos sólidos e consumo de recursos naturais na operação. O quinto, gestão ambiental interna, foi ampliado para gestão e atendimento à legislação e certificações. O construto foi considerado condição intermediária e necessária para os demais. Outros construtos poderiam ter sido usados. A distribuição de importância relativa entre construtos ocorre por métodos multicriteriais de apoio à decisão. Nos casos deste artigo, cada especialista do grupo ordenou os cinco construtos conforme sua opinião (do mais para o menos importante) e distribuiu quinze pontos segundo a escala do Quadro 1 (p. ex., cinco especialistas, setenta e cinco pontos). Os pontos de cada construto foram somados e os resultados normalizados. Os valores normalizados formam um vetor de prioridades ou importâncias relativas atribuídas aos construtos.

Em seguida, sempre mediados por pesquisador, os especialistas definem indicadores que apreendam e expliquem os construtos. Nos quatro primeiros casos, a distribuição de importância entre os indicadores foi uniforme. No quinto, os gestores decidiram distribuir importância também entre os indicadores. Na fase de avaliação, a situação de cada indicador é julgada por gestores das operações por meio de questionários e escalas. No questionário consta: Para os quesitos (seguem os indicadores), indique a sua opinião sobre o atual desempenho ambiental. As opções são: [ótimo $=1 ;$ bom $=0,75 ;$ médio $=0,5 ;$ ruim $=0,25$; péssimo $=0]$.

A última etapa é a composição dos julgamentos. A contribuição do indicador para o desempenho, em pontos percentuais (pp), é obtida multiplicando desempenho e importância. O resultado final é a soma das contribuições individuais, ficando entre $0 \%$ e $100 \%$. Se todos os desempenhos de indicadores forem julgados ótimos, o desempenho final será de $100 \%$.

\subsection{Casos de aplicação}

O primeiro caso ocorreu em uma empresa avícola que é produtora, industrializadora e comercializadora

Quadro 1. Escala para distribuir importância entre os construtos.

\begin{tabular}{|lc|}
\hline \multicolumn{1}{|c|}{ Posição do construto } & Pontuação \\
\hline Mais importante & 5 pontos \\
Segundo em importância & 4 pontos \\
Terceiro em importância & 3 pontos \\
Quarto em importância & 2 pontos \\
Menos importante & 1 ponto \\
\hline
\end{tabular}

de ovos. A empresa tem duzentos e dez funcionários em atividades agroindustriais e fabris. Cinco especialistas em gestão ambiental estudaram a operação e participaram das sessões de grupo focado, mediadas por pesquisadores, nas quais distribuíram importância entre os cinco construtos e definiram vinte e nove indicadores que os explicam. O julgamento é válido exclusivamente para a operação, na época estudada. Outros especialistas, outra operação ou outra época podem produzir outros resultados. Quinze funcionários, em nível de decisão, participaram da avaliação: gerente administrativo; gerente operacional; gerente industrial; gerente de exportação; supervisores da fábrica de rações; supervisores de entrepostos de ovos; supervisor de fomento rural; gestor do sistema de qualidade; facilitadores do sistema de qualidade; e operador de ETE e ETA (Estação de Tratamento de Efluentes e Estação de Tratamento de Águas).

O modelo de avaliação de desempenho é sintetizado na Tabela 1. O formato de construção da tabela é o mesmo para todos os casos e valem as mesmas considerações.

Na primeira coluna, surgem os construtos e as importâncias relativas, calculadas pela soma das avaliações dos cinco especialistas, conforme a escala do Quadro 1. Nas próximas duas colunas, surgem os indicadores e as importâncias relativas, uniformemente distribuídas dentro do construto. As importâncias são informadas em percentagem e devem somar $100 \%$.

Nas duas últimas colunas, surgem os desempenhos dos indicadores, os desempenhos dos construtos e as lacunas dos construtos. Estas grandezas são informadas em pontos percentuais, para que não sejam tomadas como percentagens absolutas e sim como parcelas da importância relativa. Por exemplo, o indicador efluentes de higienização dos aviários tem uma importância de $6 \%$ e a média das respostas dos avaliadores foi 0,5 (50\% do máximo possível), o que representa um desempenho de 3 pp $(0,5 \times 6 \%)$. A lacuna é o quanto o construto deixou de contribuir para o máximo desempenho possível. Por exemplo, o construto emissões atmosféricas poderia contribuir com $13 \mathrm{pp}$, mas atingiu 9,75 pp, o que perfaz uma lacuna de 3,25 pp. Os construtos com maiores lacunas devem ser priorizados em planos de correção de desempenho ambiental. Decidiu-se calcular lacunas de construtos e não de indicadores por assumir-se que indicadores do mesmo construto podem estar correlacionados, ou seja, ações que interferem em um também interferem em outros. Por exemplo, em efluentes líquidos, uma ação de melhoria nos efluentes do aviário também pode melhorar os efluentes de lavagem do produto (primeiro e segundo indicadores).

Na última linha, resultante da soma dos desempenhos individuais dos indicadores, surge o desempenho ambiental da operação, um número entre 0 e $100 \%$. 
Tabela 1. Modelo para avaliação de desempenho ambiental da operação avícola.

\begin{tabular}{|c|c|c|c|c|c|}
\hline \multirow[b]{2}{*}{ Construto } & \multirow[b]{2}{*}{ Indicador } & \multicolumn{4}{|c|}{ Desempenho } \\
\hline & & $\begin{array}{c}\text { Importância } \\
(\%)\end{array}$ & Indicador & Construto & $\begin{array}{c}\text { Lacuna no } \\
\text { construto }\end{array}$ \\
\hline \multirow{4}{*}{$\begin{array}{l}\text { Emissões } \\
\text { atmosféricas } \\
13 \%\end{array}$} & Emissões de $\mathrm{CO}, \mathrm{CO}_{2}, \mathrm{SO}_{2}$ (combustíveis) & 3,25 & $2,44 \mathrm{pp}$ & $9,75 \mathrm{pp}$ & $3,25 \mathrm{pp}$ \\
\hline & Emissão de $\mathrm{CH}_{4}$ (putrefação de aves mortas) & 3,25 & $2,44 \mathrm{pp}$ & - & - \\
\hline & Emissões de gás de refrigeração & 3,25 & $3,25 \mathrm{pp}$ & - & - \\
\hline & Queima de matéria-prima para ração & 3,25 & $1,63 \mathrm{pp}$ & - & - \\
\hline \multirow{4}{*}{$\begin{array}{l}\text { Efluentes } \\
\text { líquidos } \\
24 \%\end{array}$} & Efluentes de higienização dos aviários & 6,00 & $3,00 \mathrm{pp}$ & $19,5 \mathrm{pp}$ & $4,5 \mathrm{pp}$ \\
\hline & Efluentes de lavagem de ovos & 6,00 & $6,00 \mathrm{pp}$ & - & - \\
\hline & Efluentes de sanitização de veículos & 6,00 & $4,50 \mathrm{pp}$ & - & - \\
\hline & Efluentes líquidos da administração & 6,00 & $6,00 \mathrm{pp}$ & - & - \\
\hline \multirow{9}{*}{$\begin{array}{l}\text { Resíduos } \\
\text { sólidos } \\
33 \%\end{array}$} & Materiais recicláveis & 3,67 & $2,75 \mathrm{pp}$ & $24,77 \mathrm{pp}$ & $8,23 \mathrm{pp}$ \\
\hline & Aves mortas & 3,67 & $3,67 \mathrm{pp}$ & - & - \\
\hline & Embalagens de vacinas & 3,67 & $1,84 \mathrm{pp}$ & - & - \\
\hline & Cascas de ovos & 3,67 & $2,75 \mathrm{pp}$ & - & - \\
\hline & Resíduos orgânicos & 3,67 & $3,67 \mathrm{pp}$ & - & - \\
\hline & Fezes de aves & 3,67 & $2,75 \mathrm{pp}$ & - & - \\
\hline & Resíduos flotados e decantados (ETE e ETA) & 3,67 & $1,84 \mathrm{pp}$ & - & - \\
\hline & Lâmpadas & 3,67 & $2,75 \mathrm{pp}$ & - & - \\
\hline & Cinzas de caldeiras & 3,67 & $2,75 \mathrm{pp}$ & - & - \\
\hline \multirow{7}{*}{$\begin{array}{l}\text { Uso de } \\
\text { recursos } \\
23 \%\end{array}$} & Emprego do sola & 3,29 & $1,65 \mathrm{pp}$ & $16,45 \mathrm{pp}$ & $6,55 \mathrm{pp}$ \\
\hline & Emprego de matéria-prima & 3,29 & $3,29 \mathrm{pp}$ & - & - \\
\hline & Consumo de água & 3,29 & $2,47 \mathrm{pp}$ & - & - \\
\hline & Consumo de energia elétrica & 3,29 & $2,47 \mathrm{pp}$ & - & - \\
\hline & Emprego de combustíveis fósseis & 3,29 & $2,47 \mathrm{pp}$ & - & - \\
\hline & Emprego de combustíveis vegetais (lenha) & 3,29 & $2,47 \mathrm{pp}$ & - & - \\
\hline & Emprego de minerais (gesso e calcário) & 3,29 & $1,65 \mathrm{pp}$ & - & - \\
\hline \multirow{5}{*}{$\begin{array}{l}\text { Gestão e } \\
\text { atendimento } \\
\text { à legislação } \\
7 \%\end{array}$} & Leis municipais & 1,40 & $1,40 \mathrm{pp}$ & $6,65 \mathrm{pp}$ & $0,35 \mathrm{pp}$ \\
\hline & Leis estaduais & 1,40 & $1,40 \mathrm{pp}$ & - & - \\
\hline & Leis federais & 1,40 & $1,40 \mathrm{pp}$ & - & - \\
\hline & Requisitos para comercialização & 1,40 & $1,05 \mathrm{pp}$ & - & - \\
\hline & Notificações ambientais & 1,40 & $1,40 \mathrm{pp}$ & - & - \\
\hline $100 \%$ & total $=$ & 100 & $77,12 \%$ & - & - \\
\hline
\end{tabular}

O segundo caso ocorreu em uma manufatura de materiais elétricos, principalmente cabos elétricos especiais, tubos isolantes e resistores elétricos flexíveis. A empresa opera com cerca de sessenta funcionários. Quatro especialistas em gestão ambiental estudaram a operação e em grupo focado mediado por pesquisadores distribuíram importância entre os construtos e definiram dezoito indicadores. Dez funcionários, em nível de decisão, participaram da fase de avaliação: gerentes administrativo, comercial, de engenharia, industrial e supervisores de etapas da produção. O modelo é sintetizado na Tabela 2. As maiores lacunas são emissões atmosféricas e resíduos sólidos. O terceiro caso ocorreu em uma empresa de manufatura de materiais mecânicos, principalmente peças forjadas e usinadas, que opera com cerca de duzentos funcionários. Cinco especialistas em gestão ambiental estudaram a operação e participaram das sessões de grupo focado nas quais distribuíram importância entre os construtos e definiram vinte e quatro indicadores. Dez funcionários, em nível de decisão, participaram da fase de avaliação: gerentes de produção e de engenharia, industrial e supervisores de etapas da produção. O modelo é sintetizado na Tabela 3. As maiores lacunas são uso de recursos naturais e energéticos e efluentes líquidos. O quarto caso ocorreu em fábrica de rações para frangos e suínos, especificamente nas operações de mistura, peletização, secagem e resfriamento. Quatro especialistas em gestão ambiental estudaram as operações e participaram das sessões 
Tabela 2. Modelo para avaliação de desempenho ambiental da fabricação de materiais elétricos.

\begin{tabular}{llcccc}
\hline Construto & \multicolumn{1}{c}{ Indicador } & $\begin{array}{c}\text { Importância } \\
(\%)\end{array}$ & Indicador & Construto & $\begin{array}{c}\text { Lacuna no } \\
\text { construto }\end{array}$ \\
\hline Emissões & Emissões de poeira & 8,67 & $5,20 \mathrm{pp}$ & $11,05 \mathrm{pp}$ & $14,95 \mathrm{pp}$ \\
atmosféricas & Emissão de ácido clorídrico & 8,67 & $2,17 \mathrm{pp}$ & - & - \\
$26 \%$ & Emissão de gases de combustão & 8,67 & $3,68 \mathrm{pp}$ & - & - \\
Efluentes & Água de trefilação & 4,33 & $3,03 \mathrm{pp}$ & $8,63 \mathrm{pp}$ & $4,37 \mathrm{pp}$ \\
líquidos & Água de processo & 4,33 & $3,22 \mathrm{pp}$ & - & - \\
$13 \%$ & Água de caldeirão & 4,33 & $2,38 \mathrm{pp}$ & - & - \\
Resíduos & Resíduos de cobre & 3,67 & $3,30 \mathrm{pp}$ & $10,99 \mathrm{pp}$ & $11,01 \mathrm{pp}$ \\
sólidos & Resíduos de silicone & 3,67 & $1,65 \mathrm{pp}$ & - & - \\
$22 \%$ & Resíduos de PVC & 3,67 & $2,01 \mathrm{pp}$ & - & - \\
& Resíduos de EPR & 3,67 & $0,55 \mathrm{pp}$ & - & - \\
& Resíduos de teflon & 3,67 & $1,47 \mathrm{pp}$ & - & - \\
Uso de & Resíduos de embalagens & 3,67 & $2,02 \mathrm{pp}$ & - & - \\
recursos & Emprego de energia elétrica & 10,33 & $8,76 \mathrm{pp}$ & $23,23 \mathrm{pp}$ & $7,77 \mathrm{pp}$ \\
$31 \%$ & Emprego de água & 10,33 & $7,75 \mathrm{pp}$ & - & - \\
Gestão e & Emprego de cobre & 10,33 & $6,72 \mathrm{pp}$ & - & - \\
atendimento & Atendimento à FEPAM & 2,67 & $2,14 \mathrm{pp}$ & $6,68 \mathrm{pp}$ & $1,32 \mathrm{pp}$ \\
à legislação & Atendimento à SMAMM & 2,67 & $2,40 \mathrm{pp}$ & - & - \\
$8 \%$ & Atendimento ao IBAMA & 2,67 & $2,14 \mathrm{pp}$ & - & - \\
\multicolumn{1}{c}{$100 \%$} & $\quad-$ & - & - & - & - \\
\hline & total = & 100 & $60,6 \%$ & - & - \\
\hline
\end{tabular}

Tabela 3. Modelo para avaliação de desempenho ambiental da fabricação de materiais mecânicos.

\begin{tabular}{|c|c|c|c|c|c|}
\hline \multirow[b]{2}{*}{ Construto } & \multirow[b]{2}{*}{ Indicador } & \multicolumn{4}{|c|}{ Desempenho } \\
\hline & & $\begin{array}{c}\text { Importância } \\
(\%)\end{array}$ & Indicador & Construto & $\begin{array}{l}\text { Lacuna no } \\
\text { construto }\end{array}$ \\
\hline \multirow{5}{*}{$\begin{array}{l}\text { Emissões } \\
\text { atmosféricas } \\
15 \%\end{array}$} & Emissões de orgânicos voláteis & 3 & $1,80 \mathrm{pp}$ & 9,24 pp & $5,76 \mathrm{pp}$ \\
\hline & Emissão de $\mathrm{CO}$ e $\mathrm{CO}_{2}$ & 3 & $1,80 \mathrm{pp}$ & - & - \\
\hline & Emissões de matérias-primas armazenadas & 3 & $1,95 \mathrm{pp}$ & - & - \\
\hline & Emissões de amônia & 3 & $1,29 \mathrm{pp}$ & - & - \\
\hline & Emissões de gases de solda & 3 & $2,40 \mathrm{pp}$ & - & - \\
\hline \multirow{4}{*}{$\begin{array}{l}\text { Efluentes } \\
\text { líquidos } \\
25 \%\end{array}$} & Esgoto cloacal & 6,25 & $3,12 \mathrm{pp}$ & $15,19 \mathrm{pp}$ & $9,81 \mathrm{pp}$ \\
\hline & Óleos e graxas & 6,25 & $4,56 \mathrm{pp}$ & - & - \\
\hline & Efluentes da fosfatização & 6,25 & $3,12 \mathrm{pp}$ & - & - \\
\hline & Emulsões oleosas & 6,25 & $4,37 \mathrm{pp}$ & - & - \\
\hline \multirow{6}{*}{$\begin{array}{l}\text { Resíduos } \\
\text { sólidos } \\
20 \%\end{array}$} & Resíduos de carepa de forjaria & 3,33 & $2,43 \mathrm{pp}$ & $15,05 \mathrm{pp}$ & $4,95 \mathrm{pp}$ \\
\hline & Resíduos de cavaco de ferro & 3,33 & $2,60 \mathrm{pp}$ & - & - \\
\hline & Resíduos de manta e borra de retífica & 3,33 & $2,76 \mathrm{pp}$ & - & - \\
\hline & Resíduos recicláveis & 3,33 & $2,26 \mathrm{pp}$ & - & - \\
\hline & Resíduos de borra de tinta & 3,33 & $2,66 \mathrm{pp}$ & - & - \\
\hline & Resíduos de materiais orgânicos & 3,33 & $2,33 \mathrm{pp}$ & - & - \\
\hline \multirow{5}{*}{$\begin{array}{l}\text { Uso de } \\
\text { recursos } \\
35 \%\end{array}$} & Emprego de gás natural & 7 & $3,85 \mathrm{pp}$ & $18,06 \mathrm{pp}$ & $16,94 \mathrm{pp}$ \\
\hline & Emprego de água & 7 & $3,15 \mathrm{pp}$ & - & - \\
\hline & Emprego de energia elétrica & 7 & $3,15 \mathrm{pp}$ & - & - \\
\hline & Emprego de ligas metálicas e aço & 7 & $3,71 \mathrm{pp}$ & - & - \\
\hline & Emprego de madeira & 7 & $4,20 \mathrm{pp}$ & - & - \\
\hline \multirow{3}{*}{$\begin{array}{l}\text { Gestão e } \\
\text { atendimento } \\
5 \%\end{array}$} & Atendimento ao Estado & 1,25 & $0,97 \mathrm{pp}$ & $3,79 \mathrm{pp}$ & $2,21 \mathrm{pp}$ \\
\hline & Atendimento à União & 1,25 & $0,97 \mathrm{pp}$ & - & - \\
\hline & Certificação ISO 14001 & 1,25 & $0,85 \mathrm{pp}$ & - & - \\
\hline $100 \%$ & total $=$ & 100 & $61,34 \%$ & - & - \\
\hline
\end{tabular}


Tabela 4. Modelo para avaliação de desempenho ambiental da fabricação de rações.

\begin{tabular}{|c|c|c|c|c|c|}
\hline \multirow[b]{2}{*}{ Construto } & \multirow[b]{2}{*}{ Indicador } & \multicolumn{4}{|c|}{ Desempenho } \\
\hline & & $\begin{array}{c}\text { Importância } \\
(\%)\end{array}$ & Indicador & Construto & $\begin{array}{c}\text { Lacuna no } \\
\text { construto }\end{array}$ \\
\hline \multirow{6}{*}{$\begin{array}{l}\text { Emissões } \\
\text { atmosféricas } \\
27 \%\end{array}$} & Poeiras & 4,5 & $0,95 \mathrm{pp}$ & $12,24 \mathrm{pp}$ & $14,76 \mathrm{pp}$ \\
\hline & Material particulado & 4,5 & $1,13 \mathrm{pp}$ & - & - \\
\hline & Odores & 4,5 & $2,43 \mathrm{pp}$ & - & - \\
\hline & Ruído ambiental & 4,5 & $2,43 \mathrm{pp}$ & - & - \\
\hline & Emissão de $\mathrm{CO}$ e $\mathrm{CO}_{2}$ & 4,5 & $2,25 \mathrm{pp}$ & - & - \\
\hline & Emissão de $\mathrm{NO}_{x}$ & 4,5 & $3,06 \mathrm{pp}$ & - & - \\
\hline \multirow{3}{*}{$\begin{array}{l}\text { Efluentes } \\
\text { líquidos } \\
26 \%\end{array}$} & Água de caldeira & 6,25 & $5,55 \mathrm{pp}$ & $14,47 \mathrm{pp}$ & $11,53 \mathrm{pp}$ \\
\hline & Água de lavagem industrial & 6,25 & $2,77 \mathrm{pp}$ & - & - \\
\hline & Efluentes sanitários & 6,25 & $2,43 \mathrm{pp}$ & - & - \\
\hline \multirow{7}{*}{$\begin{array}{l}\text { Resíduos } \\
\text { sólidos } \\
14 \%\end{array}$} & Embalagens de matérias-primas & 2 & $1,86 \mathrm{pp}$ & $12,5 \mathrm{pp}$ & $1,5 \mathrm{pp}$ \\
\hline & Resíduos de metais & 2 & $1,86 \mathrm{pp}$ & - & - \\
\hline & Material de escritório & 2 & $1,42 \mathrm{pp}$ & - & - \\
\hline & Resíduo de limpeza de caldeira & 2 & $1,86 \mathrm{pp}$ & - & - \\
\hline & Resíduos de borrachas e pneus & 2 & $1,86 \mathrm{pp}$ & - & - \\
\hline & Coleta de varrição & 2 & $1,86 \mathrm{pp}$ & - & - \\
\hline & Óleos e graxas & 2 & $1,78 \mathrm{pp}$ & - & - \\
\hline \multirow{5}{*}{$\begin{array}{l}\text { Uso de } \\
\text { recursos } \\
27 \%\end{array}$} & Matéria-prima (milho e soja) & 5,4 & $2,48 \mathrm{pp}$ & $16,96 \mathrm{pp}$ & $10,04 \mathrm{pp}$ \\
\hline & Lenha & 5,4 & $2,48 \mathrm{pp}$ & - & - \\
\hline & Óleo diesel & 5,4 & $4,05 \mathrm{pp}$ & - & - \\
\hline & Eletricidade & 5,4 & $4,64 \mathrm{pp}$ & - & - \\
\hline & Água & 5,4 & $3,29 \mathrm{pp}$ & - & - \\
\hline \multirow{5}{*}{$\begin{array}{l}\text { Gestão e } \\
\text { atendimento } \\
\text { à legislação } \\
7 \%\end{array}$} & Municipal & 1,4 & $0,99 \mathrm{pp}$ & $5,33 \mathrm{pp}$ & $1,67 \mathrm{pp}$ \\
\hline & Estadual & 1,4 & $0,99 \mathrm{pp}$ & - & - \\
\hline & Federal & 1,4 & $1,05 \mathrm{pp}$ & - & - \\
\hline & Certificação ISO 14001 e APPCC & 1,4 & $1,05 \mathrm{pp}$ & - & - \\
\hline & SEFAG & 1,4 & $1,25 \mathrm{pp}$ & - & - \\
\hline $100 \%$ & total $=$ & 100 & $61,5 \%$ & - & - \\
\hline
\end{tabular}

de grupo focado, chegando a vinte indicadores. Sete funcionários, em nível de decisão, participaram da avaliação: gerente de produção, coordenadores de dois turnos de produção, de qualidade e de manutenção, técnico de segurança e estagiário de nível superior do setor de meio ambiente. O modelo é sintetizado na Tabela 4. As maiores lacunas foram emissões atmosféricas e efluentes líquidos. Chamou a atenção o desempenho em resíduos sólidos, cuja lacuna é de apenas 1,5 ponto percentual.

O quinto caso ocorreu em uma operação de estamparia de chapas para montadoras de veículos e de equipamentos eletromecânicos. Os principais produtos são peças estampadas, conjuntos soldados e cabines para veículos automotores. A empresa tem quatro unidades operacionais, três em São Paulo e uma no Rio Grande do Sul, que sediou o caso. No total, são cerca de seiscentos funcionários. Cinco especialistas estudaram a operação, distribuíram importância e chegaram a vinte e seis indicadores.
Sete gestores da empresa participaram do estudo. Estes sugeriram e o pesquisador acolheu a sugestão de distribuir importância relativa também entre os indicadores dentro de cada construto. Foi usado o mesmo método e o resultado parece ser uma contribuição do caso à pesquisa. $\mathrm{O}$ modelo de desempenho é sintetizado na Tabela 5. As maiores lacunas foram emissões atmosféricas e efluentes líquidos.

\subsection{Discussão dos casos}

Os resultados dos casos foram apresentados aos especialistas e gestores das empresas que participaram da pesquisa e com eles discutidos. Ao fim, discutiu-se também o método.

No primeiro caso, operação avícola, as maiores lacunas de desempenho foram resíduos sólidos, com 8,23 pp em 33 possíveis (desempenho relativo de $75 \%$ ) e uso de recursos, com 6,55 pp em 23 (71,5\%). 
Tabela 5. Modelo para avaliação de desempenho ambiental da operação de estamparia.

\begin{tabular}{|c|c|c|c|c|c|}
\hline \multirow[b]{2}{*}{ Construto } & \multirow[b]{2}{*}{ Indicador } & \multicolumn{4}{|c|}{ Desempenho } \\
\hline & & $\begin{array}{c}\text { Importância } \\
(\%)\end{array}$ & Indicador & Construto & $\begin{array}{c}\text { Lacuna no } \\
\text { construto }\end{array}$ \\
\hline \multirow{3}{*}{$\begin{array}{l}\text { Emissões } \\
\text { atmosféricas } \\
8,34 \%\end{array}$} & Fumaça preta & 2,08 & $1,04 \mathrm{pp}$ & $5,63 \mathrm{pp}$ & $2,6 \mathrm{pp}$ \\
\hline & Ruído ambiental & 6,25 & $4,69 \mathrm{pp}$ & - & - \\
\hline & - & - & - & - & - \\
\hline \multirow{5}{*}{$\begin{array}{l}\text { Efluentes } \\
\text { líquidos } \\
23,61 \%\end{array}$} & Óleos hidráulicos & 9,44 & $7,08 \mathrm{pp}$ & $12,4 \mathrm{pp}$ & $11,21 \mathrm{pp}$ \\
\hline & Óleo de cozinha & 7,08 & $1,77 \mathrm{pp}$ & - & - \\
\hline & Efluentes sanitários & 1,18 & $0,59 \mathrm{pp}$ & - & - \\
\hline & Efluentes de cozinha & 4,72 & $2,36 \mathrm{pp}$ & - & - \\
\hline & Efluentes vestiários & 1,18 & $0,59 \mathrm{pp}$ & - & - \\
\hline \multirow{10}{*}{$\begin{array}{l}\text { Resíduos } \\
\text { sólidos } \\
33,34 \%\end{array}$} & Sobras de alimentos & 0,13 & $0 \mathrm{pp}$ & $28,2 \mathrm{pp}$ & $5,14 \mathrm{pp}$ \\
\hline & Plástico com óleo & 5,33 & $4 \mathrm{pp}$ & - & - \\
\hline & Papelão com óleo & 5,33 & $4 \mathrm{pp}$ & - & - \\
\hline & Panos contaminados de oficina & 3,33 & $2,5 \mathrm{pp}$ & - & - \\
\hline & Resíduos de varrição da fábrica & 1,83 & $0,46 \mathrm{pp}$ & - & - \\
\hline & Borra de retífica & 5 & $5 \mathrm{pp}$ & - & - \\
\hline & Resíduos de madeiras & 1,67 & $1,67 \mathrm{pp}$ & - & - \\
\hline & Sucata metálica & 10 & $10 \mathrm{pp}$ & - & - \\
\hline & Papel, papelão e plásticos de escritório & 0,54 & $0,4 \mathrm{pp}$ & - & - \\
\hline & Cartuchos e resíduos de impressora & 0,17 & $0,17 \mathrm{pp}$ & - & - \\
\hline \multirow{4}{*}{$\begin{array}{l}\text { Uso de } \\
\text { recursos } \\
15,28 \%\end{array}$} & Água & 0,76 & $0,38 \mathrm{pp}$ & $10,89 \mathrm{pp}$ & $4,39 \mathrm{pp}$ \\
\hline & Eletricidade & 4,58 & $3,44 \mathrm{pp}$ & - & - \\
\hline & GLP (gás liquefeito de petróleo) & 0,76 & $0,19 \mathrm{pp}$ & - & - \\
\hline & Aço & 9,17 & $6,88 \mathrm{pp}$ & - & - \\
\hline \multirow{5}{*}{$\begin{array}{l}\text { Gestão e } \\
\text { atendimento } \\
\text { à legislação } \\
19,44 \%\end{array}$} & Municipal & 3,89 & $3,89 \mathrm{pp}$ & $16,53 \mathrm{pp}$ & $2,91 \mathrm{pp}$ \\
\hline & Estadual & 3,89 & $3,89 \mathrm{pp}$ & - & - \\
\hline & Federal & 3,89 & $3,89 \mathrm{pp}$ & - & - \\
\hline & NBRs, NRs, resoluções, decretos & 3,89 & $3,89 \mathrm{pp}$ & - & - \\
\hline & SGA & 3,89 & $0,97 \mathrm{pp}$ & - & - \\
\hline $100 \%$ & total $=$ & 100 & $73,65 \%$ & - & - \\
\hline
\end{tabular}

As demais lacunas foram inferiores a $5 \mathrm{pp}$. Caso a empresa decida formular uma estratégia para melhorar seu desempenho ambiental, as ações mais promissoras, por terem seus indicadores mais mal avaliados, são em embalagens de vacinas e resíduos flotados e decantados das ETE e ETA (estação de tratamento de águas). As menos promissoras, por já serem foco de ação gerencial (por isto receberam avaliação máxima), são ações em resíduos orgânicos e aves mortas. A pesquisa não ofereceu informações de custo ou esforço requerido para a execução das ações.

No segundo caso, manufatura de materiais elétricos, as maiores lacunas foram emissões atmosféricas, com 14,95 pp em 26 possíveis (42,5\%) e resíduos sólidos, com 11 pp em 22 (50\%). As demais foram inferiores a 8 pp. As ações mais promissoras são em emissão de ácido clorídrico, resíduos de teflon, resíduos de silicone e emprego de cobre. As menos promissoras, por já serem rotina, são ações de atendimento à legislação.

No terceiro caso, manufatura mecânica, as maiores lacunas foram uso de recursos, com 16,94 pp em 35 possíveis (51\%) e efluentes líquidos, com $9,81 \mathrm{pp}$ em 25 (61\%). As ações mais promissoras são em emprego de água e energia elétrica e tratamento de esgotos e efluentes da fostatização. As menos promissoras são em atendimento à legislação.

No quarto caso, fabricação de rações, as maiores lacunas foram efluentes líquidos, com 14,76 pp em 27 possíveis $(45 \%)$ e resíduos sólidos, com 11,53 pp em 26 (55,6\%). Chama a atenção o desempenho do construto resíduos sólidos, cuja lacuna é de apenas 1,5 pp em 14 (89\%). As ações mais promissoras são em poeira, material particulado e efluentes sanitários. As menos promissoras são em resíduos sólidos e atendimento à legislação, pois estes aspectos já são 
contemplados suficientemente nas rotinas de gestão da operação.

No quinto caso, estamparia, as maiores lacunas foram efluentes líquidos, com 11,21 pp em 23,61 possíveis $(52,5 \%)$ e resíduos sólidos, com 5,14 pp em 33,34 (84,6\%). Emissões atmosféricas são pouco importantes, pois não há processo térmico e foram consideradas apenas emissões veiculares. As ações mais promissoras são em efluentes sanitários, efluentes de vestiários e óleo de cozinha. As menos promissoras são em atendimento a legislações, que são cumpridas rotineira e integralmente, exceção feita ao SGA, recém iniciado e com quase tudo ainda por fazer, segundo os gestores.

Cabem considerações conjuntas sobre os cinco casos.

A Tabela 6 sintetiza e ordena os tamanhos das lacunas dos construtos caso a caso. Nas colunas, surgem os valores e o posto das lacunas por construto por operação. Na última coluna, são ordenadas as lacunas totais das cinco operações. Na última linha, são apresentadas as médias das colunas. A Figura 1 apresenta a distribuição das lacunas de desempenho nos casos. Observa-se que o construto consumo de recursos é o de maior média lacunar, sendo a melhor oportunidade de melhorias nos casos estudados. Emissões atmosféricas e efluentes líquidos são oportunidades intermediárias. Em penúltimo e último lugar vêm respectivamente resíduos sólidos e gestão e atendimento à legislação, este afastado dos demais. A menor lacuna (operação avícola) corresponde ao melhor desempenho ambiental avaliado $(77,1 \%)$. Todos os construtos, menos legislação, comparecem ao menos uma vez como a maior lacuna. Já legislação só ocupa os dois últimos postos. Caso o SGA fosse retirado do construto no $5^{\circ}$ caso e o desempenho em resíduos sólidos não fosse tão alto no $4^{\circ}$ caso, legislação seria sempre o construto de

Tabela 6. Ordenação das lacunas de desempenho.

\begin{tabular}{lllllll}
\hline & $\begin{array}{c}\text { Emissões } \\
\text { atmosféricas }\end{array}$ & $\begin{array}{c}\text { Efluentes } \\
\text { líquidos }\end{array}$ & $\begin{array}{c}\text { Resíduos } \\
\text { sólidos }\end{array}$ & $\begin{array}{c}\text { Consumo de } \\
\text { recursos }\end{array}$ & $\begin{array}{c}\text { Gestão e } \\
\text { atendimento } \\
\text { à legislação }\end{array}$ & $\begin{array}{c}\text { Lacuna } \\
\text { total de } \\
\text { desempenho }\end{array}$ \\
\hline Operação avícola & $4^{\circ}(3,25 \mathrm{pp})$ & $3^{\circ}(4,5 \mathrm{pp})$ & $1^{\circ}(8,25 \mathrm{pp})$ & $2^{\circ}(6,55 \mathrm{pp})$ & $5^{\circ}(0,35 \mathrm{pp})$ & $22,9 \mathrm{pp}: 1^{\circ}$ \\
Materiais elétricos & $1^{\circ}(14,95 \mathrm{pp})$ & $4^{\circ}(4,37 \mathrm{pp})$ & $2^{\circ}(11,01 \mathrm{pp})$ & $3^{\circ}(7,77 \mathrm{pp})$ & $5^{\circ}(1,32 \mathrm{pp})$ & $39,4 \mathrm{pp:} 5^{\circ}$ \\
Fabricação mecânica & $3^{\circ}(5,76 \mathrm{pp})$ & $2^{\circ}(9,81 \mathrm{pp})$ & $4^{\circ}(4,95 \mathrm{pp})$ & $1^{\circ}(16,94 \mathrm{pp})$ & $5^{\circ}(2,21 \mathrm{pp})$ & $38,66 \mathrm{pp}: 4^{\circ}$ \\
Fabricação de rações & $1^{\circ}(14,7 \mathrm{pp})$ & $2^{\circ}(11,53 \mathrm{pp})$ & $5^{\circ}(1,5 \mathrm{pp})$ & $3^{\circ}(10,04 \mathrm{pp})$ & $4^{\circ}(1,67 \mathrm{pp})$ & $38,5 \mathrm{pp}: 3^{\circ}$ \\
Estamparia & $5^{\circ}(2,6 \mathrm{pp})$ & $1^{\circ}(11,21 \mathrm{pp})$ & $2^{\circ}(5,14 \mathrm{pp})$ & $3^{\circ}(4,39 \mathrm{pp})$ & $4^{\circ}(2,91 \mathrm{pp})$ & $26,35 \mathrm{pp}: 2^{\circ}$ \\
Média & $8,252 \mathrm{pp}$ & $8,284 \mathrm{pp}$ & $6,17 \mathrm{pp}$ & $9,138 \mathrm{pp}$ & $1,692 \mathrm{pp}$ & $33,162 \mathrm{pp}$ \\
\hline
\end{tabular}

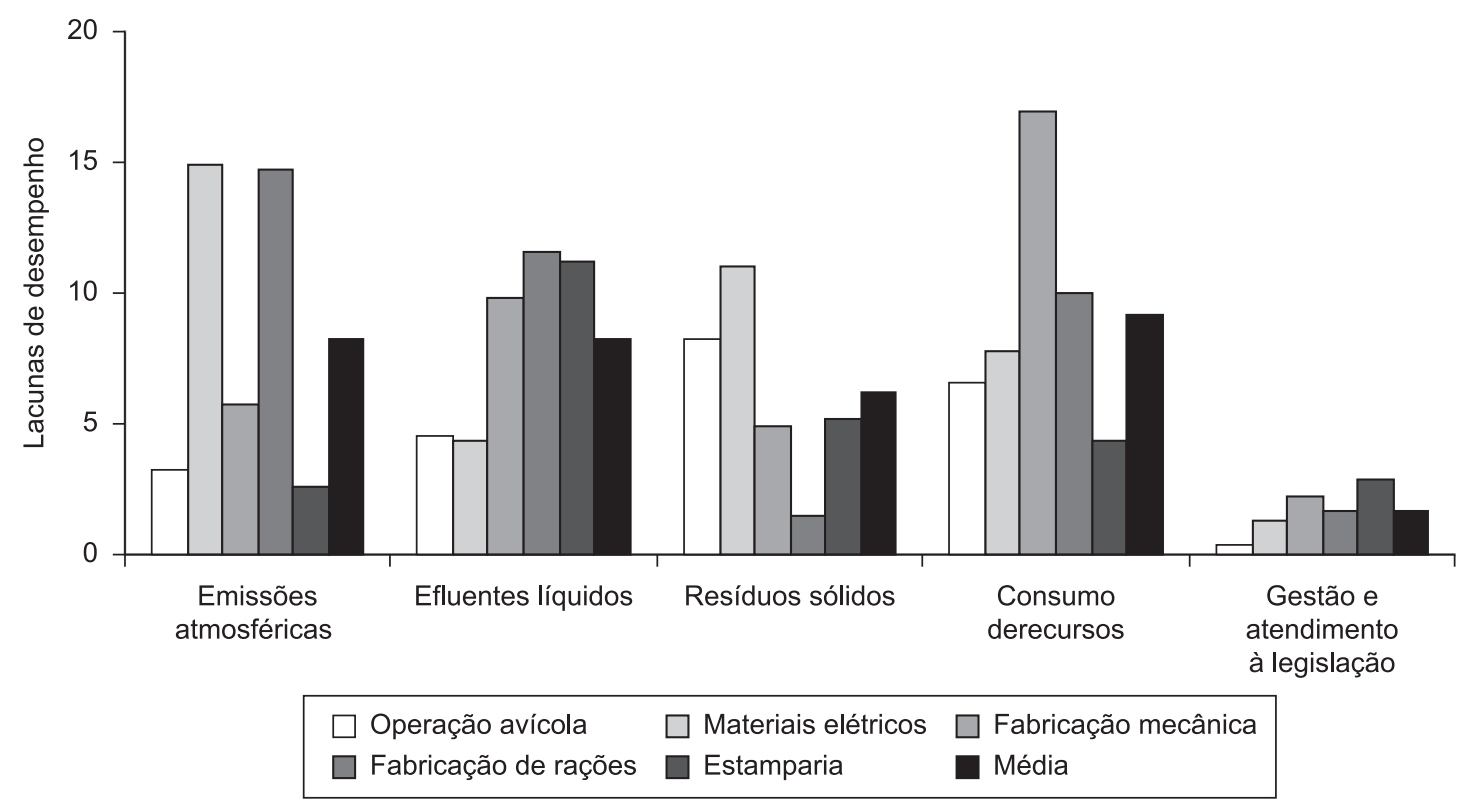

Figura 1. Visualização gráfica das lacunas de desempenho ao longo dos casos. 
menor lacuna. Os especialistas de todas as empresas estudadas afirmaram que as operações não dependem de legislação, certificação ou fiscalização para melhorar o desempenho ambiental, pois, rotineiramente, já fazem mais do que o exigido pelos preceitos legais em vigor nas sedes das operações. Contrário senso, investigações preliminares em duas operações de serviço (saneamento e transportes) mostraram que a gestão interna e o atendimento à legislação são lacunas importantes no desempenho ambiental das operações.

Ao menos em operações de manufatura, talvez não se devesse mais investigar este construto. No caso seminal, o construto investigava a qualidade do gerenciamento e das práticas gerenciais internas, o que incluía o atendimento à legislação e a obtenção e manutenção de certificações. Tais práticas foram consideradas pelos pesquisadores como condição necessária e intermediária para o surgimento dos resultados finais, apreendidos pelos quatro outros construtos. A prática dos cinco casos atuais, no entanto, não confirmou que gestão interna formalizada e atendimento à legislação fosse condição necessária. Boas práticas gerenciais foram encontradas, mesmo sem sistema formalizado de registros e eventuais certificações. Mais ainda, o simples atendimento à legislação mostrou-se insuficiente para bom desempenho ambiental em manufatura.

Passa-se, então, aos resultados finais de desempenho.

A operação avícola ficou em primeiro lugar, com desempenho ambiental de 77,1\%. A empresa opera com recursos naturais renováveis e não renováveis e expressiva parte dos executivos é formada por profissionais de ciências da terra e da vida: agrônomos, biólogos, veterinários e químicos industriais. A preocupação com a gestão de recursos naturais e impactos ambientais sempre esteve presente na história da empresa. A empresa se localiza no distrito industrial de pequeno município distante de áreas industriais. A tecnologia de produção é avançada e a gestão ambiental pareceu ter alta prioridade na estratégia de operação. Os pesquisadores ficaram com a impressão de que a preocupação ambiental nasceu junto com as operações industriais e é parte inseparável da gestão. O bom resultado da avaliação não pareceu surpreender os gestores da empresa.

O segundo lugar ficou com a operação de estamparia, com $73,65 \%$. Trata-se de operação ligada a grupo empresarial consolidado, com importantes fornecimentos às cadeias automotivas nacionais. A operação se sedia em bairro industrial muito próximo a área residencial em cidade de região metropolitana. A gestão ambiental é prioritária e a exigência da comunidade vizinha é forte, o que criou um ambiente propício para uma operação correta, a ponto de não haver processo térmico no local. Há certificações vigentes e outras em andamento, todas da família ISO 14000. O bom resultado não surpreendeu os gestores.

Os resultados dos demais casos foram parecidos e podem ser analisados em conjunto.

A fabricação de rações faz parte de uma unidade fabril maior e pertence a importante grupo empresarial multinacional. A operação é afastada de centros habitados. A unidade tem passado por transformações que ainda não se completaram no processo de produção. Os pesquisadores perceberam fragilidades na gestão ambiental, tal como desinteresse por certificações e incertezas quanto a certas práticas ambientais consolidadas em outras indústrias, tais como ecodesign e produção mais limpa. Há pouca pressão de comunidades vizinhas por melhoria de resultado ambiental, prevalecendo a noção de importância econômica da atividade para a região. Pela importância, a empresa pode e deve melhorar seu desempenho ambiental, o que foi reconhecido por gestores, principalmente adotando tecnologias mais avançadas de tratamento de emissões atmosféricas e efluentes líquidos.

A operação de fabricação mecânica se localiza em distrito industrial de região metropolitana e está sujeita a pressões de vizinhos e autoridades. Trata-se de empresa madura e consolidada, identificada com as ciências da engenharia, principalmente mecânica e metalúrgica. A preocupação com recursos naturais é recente e é menor do que a história da empresa. O nível tecnológico de produtos e processos de fabricação é elevado, atendendo a cadeias automotivas e comprando de grandes fabricantes de matéria-prima. Pela posição que ocupa, poderia ter um desempenho ambiental melhorado por técnicas de projeto de produto voltado ao ambiente (ecodesign), conservação de energia e produção mais limpa. Este tipo de técnica pode racionalizar o uso de matéria-prima (aço e ligas), energéticos e impactos ambientais, justamente os indicadores menos contributivos, segundo a avaliação.

A operação de fabricação elétrica se localiza em cidade-polo industrial. A empresa ainda está construindo sua trajetória, baseada em tecnologia de materiais elétricos. A tecnologia de produto e processo ainda não está consolidada, havendo campo para avanços, principalmente em gestão do produto. O projeto nasce mais da criatividade e inspiração isolada de projetistas do que de esforço sistematizado e controlado. Não foi observada preocupação sistematizada com o uso e tratamento dos materiais na manufatura, nem com a destinação dos resíduos de fabricação e do produto após o uso. Em síntese, se bem que haja potencial, a empresa não parece atenta para a gestão ambiental, destinando seus recursos mais para a solução de problemas de tecnologia de materiais elétricos.

Projeto voltado ao ambiente, ecodesign e produção mais limpa parecem ser técnicas adequadas para a melhoria ambiental das duas últimas operações. Como o 
ciclo de vida dos produtos parece ser curto, técnicas de logística reversa também seriam adequadas. O objetivo de tais técnicas é coletar e dar destinação adequada aos produtos após o consumo. Tal situação ocorre quando instalações e equipamentos são desativados, gerando sucata de materiais mecânicos e elétricos, tais como ferro, aço, cobre, alumínio, materiais sintéticos e ligas. Em fabricação mecânica, o mercado de reuso e reprocessamento parece mais maduro e consolidado em redes de coleta e comercialização de sucata, geralmente destinada a aciarias elétricas. Algo semelhante em fabricação elétrica ainda está por se organizar.

Passa-se ao método.

Por delimitação de pesquisa, adotaram-se os construtos do trabalho seminal de Luz, Sellitto e Gomes (2006). Em outras aplicações, outros construtos podem ser investigados. Aplicações iniciais em serviços apontaram uso do solo e conforto ambiental de pessoas como construtos promissores para a apreensão do desempenho ambiental da operação.

Quanto ao método de priorização, um objetivo de pesquisa é que não houvesse exclusão, a priori, de nenhum construto. O método de Mudge exclui uma opção se ela for unanimemente a pior. Gestão e atendimento à legislação e certificações teria sido excluído. O AHP, usado no caso seminal, evita exclusão, mas pode gerar fortes assimetrias, por exemplo, com uma prioridade dez vezes maior do que outra. Os pesquisadores criaram um método tal que a pior avaliação possível tivesse $20 \%$ do valor da melhor. Nenhum dos cinco construtos fica acima de $33,34 \%$ ou abaixo de $6,67 \%$, se houver unanimidade nos extremos. Isto ocorreu no terceiro caso e o grupo decidiu arredondar as importâncias relativas, adotando o mais próximo múltiplo de cinco pontos percentuais. Caso estes limites não sejam satisfatórios, outra escala deve ser adotada, como, por exemplo: [mais importante $=7$; ..; menos importante $=1]$. O total de pontos em distribuição passa a ser vinte e os limites de importância passam a ser 35 e $5 \%$. Para outro número de construtos, os limites serão outros.

Por fim, quanto aos itens avaliados, não se espera que um ou poucos indicadores tenham a capacidade de apreender todos os aspectos de um objeto complexo, tal como um construto de desempenho ambiental. Houve construtos em que os especialistas consideraram necessário mensurar nove indicadores. Também houve caso em que os especialistas contentaram-se com dois. Observe-se que, por ser avaliação, houve indicadores múltiplos (por exemplo, emissões de $\mathrm{CO}, \mathrm{CO}_{2}$ e $\mathrm{SO}_{2}$ ), que seriam desdobrados em mais indicadores se houvesse medição. $\mathrm{O}$ mesmo vale para o modelo como um todo. No primeiro caso, foram necessários vinte e nove indicadores para apreender toda a complexidade do objeto. No segundo, bastaram dezoito. Como há subjetividade, caso mude a complexidade da operação ou a percepção dos julgadores, os indicadores devem ser atualizados.

Quanto à mensuração, preferiu-se a categórica, por escala de julgamento. Houve sempre um número satisfatório de julgadores em cada caso, portanto entende-se que a média possa representar a situação da grandeza. No caso seminal, foram definidas faixas numéricas para as categorias dos indicadores, que foram medidos fisicamente, em mensuração objetiva. São duas as opções de pesquisa: medição, objetiva e mais custosa, pois exige mais indicadores e que devem ser medidos na natureza; ou avaliação, subjetiva, mas integrando mais aspectos nos mesmos indicadores. Sintetizando: medição é objetiva e requer mais indicadores para a apreensão de conteúdo; avaliação é subjetiva e integra mais fatores em menos indicadores.

\section{Implicações do uso do método em estratégia ambiental}

O uso do método SBP pode ter implicações em gestão estratégica ambiental.

Um aspecto do método é a flexibilidade. Se o ambiente de negócios ou as exigências ambientais mudarem, o modelo pode mudar, variando as ponderações, retirando e acrescentando indicadores ou construtos. Além de priorizar ações e apoiar a tomada de decisão, o SBP pode ser útil para comparações entre operações e pode servir como elo de realimentação para a execução de uma estratégia ambiental. À medida que esta vai sendo executada, o modelo vai informando o quanto avança o resultado final e que trocas ou realocações de recursos entre objetivos podem ser favoráveis.

Por exemplo, a operação de materiais elétricos pode melhorar o consumo de recursos ou das emissões atmosféricas realocando recursos que hoje estão na gestão de resíduos sólidos, efluentes líquidos ou gestão interna e atendimento à legislação e certificações. A fabricação mecânica pode melhorar o consumo de recursos ou os efluentes líquidos realocando recursos da gestão de resíduos sólidos, emissões atmosféricas ou gestão interna e atendimento à legislação e certificações. A fabricação de rações pode melhorar a situação das emissões atmosféricas realocando recursos atualmente destinados à gestão dos resíduos sólidos e gestão interna e atendimento à legislação e certificações.

Pode-se integrar o SBP à matriz importânciadesempenho de Slack (2002), usada por Paiva, Carvalho Jr. e Fensterseifer (2004) em estratégia de operações e adaptada para estratégia funcional em manufatura por Sellitto e Walter (2006).

Calculam-se os desempenhos relativos dos construtos, dividindo o desempenho pela importância do construto. Por exemplo, um construto com importância de 30\% e 
desempenho de $21 \mathrm{pp}$, tem desempenho relativo de $70 \%$. Faz-se um gráfico de dispersão reunindo o desempenho relativo dos construtos e a importância relativa. O gráfico é dividido em regiões. Os construtos situados na região de alto desempenho e alta importância são considerados de excelência. Na de alto desempenho e baixa importância, de excesso. Na de baixo desempenho e alta importância, de carência. Os demais, de normalidade. A execução estratégica ideal deve colocar um ou dois construtos na região de excelência e os demais na região de normalidade, de preferência ao longo da diagonal entre $(0,0)$ e a região de excelência.

Para exemplificar, a abordagem foi aplicada ao pior caso, a manufatura de materiais elétricos. A Tabela 7 apresenta as importâncias e os desempenhos relativos dos construtos. A Figura 2 traz a análise gráfica do caso. A separação das regiões foi definida arbitrariamente em um terço do âmbito da dimensão, como justificado em Sellitto e Walter (2006). Há um construto de excelência, consumo de recursos, e um de excesso, gestão e atendimento à legislação. Efluentes líquidos e emissões atmosféricas estão na região de normalidade, mas afastados da diagonal. Caso a empresa decida melhorar o desempenho ambiental global e não queira alocar novos recursos à estratégia, uma alternativa seria deslocar recursos de gestão e atendimento à legislação e efluentes líquidos para emissões atmosféricas e resíduos

Tabela 7. Informações para análise estratégica da fabricação de materiais elétricos.

\begin{tabular}{lcc}
\hline \multicolumn{1}{c}{ Construto } & $\begin{array}{c}\text { Importância } \\
\text { relativa }\end{array}$ & $\begin{array}{c}\text { Desempenho } \\
\text { relativo }\end{array}$ \\
\hline Emissões atmosféricas & $26 \%$ & $42,5 \%$ \\
Efluentes líquidos & $13 \%$ & $66,4 \%$ \\
Resíduos sólidos & $22 \%$ & $50 \%$ \\
Consumo de recursos & $31 \%$ & $75,3 \%$ \\
Gestão e atendimento & $8 \%$ & $83,5 \%$ \\
à legislação & & \\
\hline
\end{tabular}

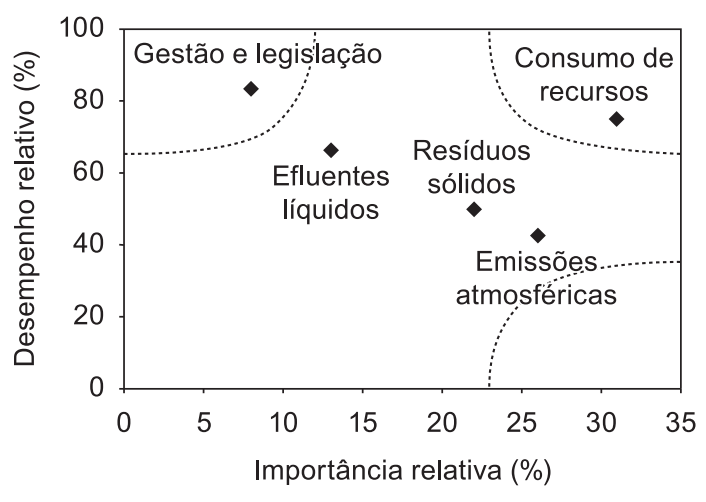

Figura 2. Análise estratégica dos construtos de desempenho ambiental da fabricação de materiais elétricos. sólidos. Para equilibrar os construtos, deveriam ser retirados mais recursos da gestão interna do que de efluentes líquidos.

Análises semelhantes podem ser feitas para os demais casos.

\section{Considerações finais}

O objetivo deste artigo foi relatar um estudo de caso quíntuplo no qual foi testado e robustecido o SBP, um método para gerar modelos capazes de mensurar o desempenho ambiental em operações de manufatura. Fizeram parte do artigo uma revisão de modelos de medição ambiental, já propostos na literatura, descrição do método e teste em cinco operações de manufatura. O estudo é exploratório e limitado à manufatura e ainda não são prudentes generalizações a outras atividades, tais como os serviços. Como o resultado final oferecido pelo método é normalizado ( 0 a 100\%), é possível formar uma série histórica de desempenho que reflita a trajetória irreversível de um fenômeno complexo, tal como o desempenho ambiental de uma operação de manufatura. Aplicações sistemáticas do método em uma indústria podem oferecer subsídios para orientar os formuladores da legislação.

O método combina técnicas de pesquisa qualitativas, como sessões de grupos focados e técnicas quantitativas, métodos multicriteriais e questionários. Nos primeiros quatro casos, a distribuição de importância relativa dos indicadores foi uniforme. No último caso, por iniciativa dos gestores respondentes, foram atribuídas prioridades aos indicadores e esta parece ter sido uma contribuição ao método. Inicialmente, os pesquisadores julgaram que haveria dificuldade em usar algum tipo de método de distribuição de importância no ambiente da manufatura. No caso, esta dificuldade não se confirmou. Outra contribuição foi a integração do SBP com a matriz importância-desempenho de Slack (2002), mencionada como método de formulação e reformulação de estratégias de operação.

Uma limitação dos casos foi o uso de avaliações, que se valem de julgamentos de especialistas, em oposição a medições, que se valem de medições físicas de variáveis de campo e de modelos matemáticos que usam as medições para o cálculo dos indicadores. Quando se usam medições físicas, são necessárias considerações estatísticas, incluindo variabilidades e distribuições, pois, geralmente, as variáveis medidas são do tipo probabilístico.

Como continuidade, propõe-se incorporar definitivamente a atribuição de prioridades aos indicadores dentro dos construtos. Também se sugere estender e testar o método em operações de serviços, tais como saneamento, transportes e educação. Aplicações preliminares já foram feitas e os resultados diferiram estruturalmente dos obtidos em manufatura. O método 
também pode ser aplicado em cadeias produtivas, como a cadeia automotiva. A aplicação ao longo de cadeias pode identificar seus pontos frágeis no desempenho ambiental. Ainda, propõem-se análises estatísticas multivariadas, do tipo fatoriais, que possam identificar componentes principais nos indicadores e eventualmente reduzir o número de julgamentos, sem redução substancial na consistência da medição. Por fim, propõe-se integrar o SBP às tecnologias de produção mais limpa (cleaner production) e ecodesign disponíveis na literatura. Entende-se que o método pode indicar as deficiências ambientais de uma operação e oferecer subsídios suficientes para apoiar a implantação e manutenção de programas de produção mais limpa e ecodesign em manufatura.

\section{Agradecimentos}

Os autores reconhecem a importância dos especialistas, oriundos do curso de Gestão Ambiental da UNISINOS, dos gestores e das empresas que participaram da pesquisa. Também reconhecem a importância das observações dos referees anônimos para a versão final do texto.

\section{Referências}

AMMENBERG, J.; HJELM, O.; QUOTES, P. The connection between environmental management systems and continual environmental performance improvements. Corporate Environmental Strategy, v. 9, n. 2, p. 183-192, 2002.

AZZONE, G.; MANZINI, R. Measuring strategic environmental performance. Business Strategy and the Environment, v. 3, n. 1, p. 1-14, 1994.

BOLLMANN, H. Indicadores ambientais. In: MAIA, N.; MARTOS, H.; BARRELLA, W. (Orgs.). Indicadores ambientais: conceitos e aplicações. São Paulo: EDUC, 2001.

BORCHARDT, M. et al. Adopting ecodesign practices: case study of a midsized automotive supplier. Environmental Quality Management, v. 19, n. 1, p. 7-22, 2009.

CAMPOS, L. SGADA: sistema de gestão e avaliação de desempenho ambiental. Uma proposta de implementação. Florianópolis, 2001. 220 p. Tese (Doutorado em Engenharia de Produção e Sistemas) Universidade Federal de Santa Catarina - UFSC.

CESARO, E. Impatto ambientale. In: LUCARELLI, F. (Org.). Dal Mediterraneo per l'Amazzonia. Napoli: Editoriale Scientifica, 1992.

CORNFORTH, I. Selecting indicators for assessing sustainable land management. Journal of Environmental Management, v. 56, n. 3, p. 173-179, 1999.

DALE, L.; GERLAK, A. It's all in the numbers: acreage tallies and environmental program evaluation. Environmental Management, v. 39, n. 2, p. 246-260, 2007.

DIAS-SARDINHA, I.; REIJNDERS, L. Evaluating environmental and social performance of large Portuguese companies: a balanced scorecard approach. Business Strategy and the Environment, v. 14, n. 2, p. 73-91, 2005.
DIAS-SARDINHA, I.; REIJNDERS, L. Environmental performance evaluation and sustainability performance evaluation of organizations: an evolutionary framework. Eco-Management and Auditing, v. 8, n. 2, p. 71-79, 2001.

DONAIRE, D. Gestão ambiental na empresa. São Paulo: Atlas, 1999.

EISENHARDT, K. Building theories from case study research. Academy of Management Review, v. 14, n. 4, p. 532-550, 1989.

FIKSEL, J. Design for environment. New York: Mc Graw Hill, 1996.

FRANKE, B.; GROTHE-SENF, A. Avaliação de desempenho ambiental ampliado (adaa): um modelo para comparação de Empresas. Revista Brasileira de Ciências Ambientais, n. 5, p. 16-21, 2006.

GOUGH, C.; CASTELLS, N.; FUNTOWICZ, S. Integrated assessment: an emerging methodology for complex issues. Environmental Modeling and Assessment, v. 3, n. 1-2, p. 19-29, 1998.

HAMMOND, A. et al. Environmental indicators: a systematic approach to measuring and reporting on environmental policy performance in the context of sustainable development. New York: World Resources Institute, 1995.

KUHRE, W. ISO 14031: environmental performance evaluation (EPE): practical tools techniques for conducting an environmental performance evaluation. Upper Saddle River: Prentice Hall, 1998.

LEEUW, F. Criteria for evaluation of smog forecast systems. Environmental Monitoring and Assessment, v. 60, n. 1, p. 1-14, 2004.

LUZ, S.; SELLITTO, M.; GOMES, L. Medição de desempenho ambiental baseada em método multicriterial de apoio à decisão: estudo de caso na indústria automotiva. Gestão \& Produção, v. 13, n. 3, p. 557-570, 2006.

MELO, J.; PEGADO, C. 2002. Ecoblock: A method for integrated environmental performance evaluation of companies and products (construction casestudy). In: INTERNATIONAL CONFERENCE ON ECOBALANCE, 5., 2002, Tsukuba. Anais... Tsukuba: The Society of Non-traditional Technology, 2002. p. 399-402.

MELO, J.; PEGADO, C. Ecoblock: a method for integrated environmental performance evaluation of companies and products. (construction case-study). Lisboa, 2006. Disponível em <http://gasa.dcea.fct.unl.pt/ecoblock/ EcoBalance_02.pdf $>$. Acesso em: 03 de maio de 2006.

MACHADO, L. Qualidade ambiental: indicadores quantitativos e perceptivos. In: MARTOS, H.; MAIA, N. (Orgs.). Indicadores ambientais. Sorocaba: USP, 1997.

OWENS, J. Life-cycle assessment: constraints on moving from inventory to impact assessment. Journal of Industrial Ecology, v. 1, n. 1, p. 37-49, 1997.

PAIVA, E.; CARVALHO JUNIOR, J.; FENSTERSEIFER, J. Estratégia de produção e de operações: conceitos, melhores práticas, visão de futuro. Porto Alegre: Bookman, 2004. 
PEARSON, J.; BARNES, T. Improve environmental performance through community action. Eco-Management and Auditing, v. 6, n. 2, p. 76-79, 1999.

PEGADO, C.; MELO J.; RAMOS, T. Ecoblock: método de avaliação do desempenho ambiental. In: CONGRESSO NACIONAL DE ENGENHEIROS DO AMBIENTE, 2001, Lisboa. Anais... Lisboa: APEA, 200. p. 1-10.

RAMOS, T.; MELO, J. Developing and implementing an environmental performance index for the portuguese military. Business Strategy and the Environment, v. 15, n. 2, p. 71-86, 2006.

ROESCH, S. Projetos de estágio e de pesquisa em administração: guia para estágios, trabalhos de conclusão, dissertações e estudos de caso. São Paulo: Atlas, 1999.

ROSSETTO, A. Proposta de um sistema integrado de gestão do ambiente urbano (SIGAU) para o desenvolvimento sustentável de cidades. Florianópolis, 2003. 404 p. Tese (Doutorado em Engenharia de Produção) - Universidade Federal de Santa Catarina - UFSC.

SELLITTO, M.; WALTER, C. Avaliação do desempenho de uma manufatura de equipamentos eletrônicos segundo critérios de competição. Produção, v. 16, n. 1, p. 34-47, 2006.

SELLITTO, M.; RIBEIRO, J. Construção de indicadores para avaliação de conceitos intangíveis em sistemas produtivos. Gestão \& Produção, v. 11, n. 1, p. 75-90, 2004.

SLACK, N. Vantagem competitiva em manufatura. São Paulo: Atlas, 2002.

THORESEN, J. Environmental performance evaluation: a tool for industrial improvement. Journal of Cleaner Production, v. 7, n. 5, p. 365-370, 1999.

TYTECA, D. On the measurement of the environmental performance of firms: a literature review and a productive efficiency perspective. Journal of Environmental Management, v. 46, n. 3, p. 281-308, 1996.

YIN, R. Estudo de caso: planejamento e método. Porto Alegre: Bookman, 2001.

ZOBEL, T. et al. Identification and assessment of environmental aspects in an EMS context: an approach to a new reproducible method based on LCA methodology Journal of Cleaner Production, v. 10, n. 4, p. 381-396, 2002. 